\title{
Confidential Care for Adolescents in the U.S. Health Care System
}

Priya R. Pathak

Adriana Chou

Follow this and additional works at: https://aah.org/jpcrr

Part of the Bioethics and Medical Ethics Commons, Health and Medical Administration Commons, Health Policy Commons, Pediatrics Commons, and the Primary Care Commons

\section{Recommended Citation}

Pathak PR, Chou A. Confidential care for adolescents in the U.S. health care system. J Patient Cent Res Rev. 2019;6:46-50. doi: 10.17294/2330-0698.1656

Published quarterly by Midwest-based health system Advocate Aurora Health and indexed in PubMed Central, the Journal of Patient-Centered Research and Reviews (JPCRR) is an open access, peer-reviewed medical journal focused on disseminating scholarly works devoted to improving patient-centered care practices, health outcomes, and the patient experience. 


\title{
Confidential Care for Adolescents in the U.S. Health Care System
}

\author{
Priya R. Pathak, MPH, ${ }^{1,2}$ Adriana Chou, $\mathrm{BA}^{2}$ \\ ${ }^{1}$ Harvard T.H. Chan School of Public Health, Boston, MA; ${ }^{2}$ University of Wisconsin School of Medicine and Public Health, \\ Madison, WI
}

\begin{abstract}
In providing care for adolescents, maintaining confidentiality should be considered a human right and an evidence-based component of quality care. Unfortunately, complexities in the U.S. legal and health care systems have created a setting in which confidential care is inaccessible to many adolescent patients. Federal laws provide a minimum standard for confidentiality protections, but variations in state legislation relating to minor consent, special health care services, and confidentiality exemptions create large variability in adolescent confidentiality rights across the country. In certain contexts, such as consensual sexual activity, legal provisions may not align with professional ethical standards in adolescent care. In addition, contemporary clinical and administrative issues related to the electronic health record and health care financing also threaten to breach confidentiality. Although further research is necessary, providers and institutions are already well positioned to broaden protections by implementing best practices in training and education, workflow, and medical records related to adolescent confidentiality. (J Patient Cent Res Rev. 2019;6:46-50.)
\end{abstract}

Keywords adolescent medicine; confidentiality; health law; best practice; health ethics

A dolescence is a unique period in development when young people make decisions and initiate behaviors that may have lifelong consequences for their health and safety. Limited access to and uptake of health services in adolescence remains a global challenge. Confidentiality concerns can be a critical barrier for young patients in seeking and receiving appropriate medical services, and confidentiality protection represents an important evidence-based practice in adolescent health care. ${ }^{1-4}$ Health care confidentiality is the "privileged and private nature of information provided during the health care transaction." 5 The international human rights community recognizes confidentiality as a component of a youth's fundamental right to privacy.

Correspondence: Priya R. Pathak, MPH, 200 Ley Avenue, Marshfield, WI 54449 (pathak.priya.r@gmail.com)
Namely, UNICEF's Implementation Handbook for the Convention on the Rights of the Child noted that "In order to promote the health and development of adolescents, States Parties are also encouraged to respect strictly their right to privacy and confidentiality, including with respect to advice and counselling on health matters."

\section{Federal Protections}

Though the right to confidentiality is recognized in the United States, the American legal and health care systems pose many challenges to the access of confidential care for adolescents. The difficulty for providers in understanding the complex national and state laws governing confidentiality and its exceptions represents a structural challenge to the provision of confidentiality. ${ }^{4,5}$ There are two main federal legal provisions meant to provide a minimum "floor" for confidentiality protection - the Health Insurance Portability and Accountability Act (HIPAA) and the Family Educational Rights and Privacy Act (FERPA). ${ }^{7}$ 
As it applies to minors, HIPAA generally allows a parent to have access to medical records for children under the age of 18 , with three exceptions: 1) when a minor obtains care at the direction of a court; 2) when a parent agrees that clinician and minor may have a confidential relationship; 3) and when a minor has consented for the care and the consent of the parent is not required by state or other applicable law. ${ }^{8}$ FERPA allows parents access to a minor's educational records, which may contain health information. However, if health records are kept separately as part of a schoolbased health center where confidentiality has been addressed, these records would instead be subject to HIPAA provisions. ${ }^{8}$

\section{Variable State Protections}

Every state has additionally enacted minor consent laws, which fall into two general categories. First, there are laws that are based on the status of the minor, which broadly include mature minor and emancipated minor laws. These laws grant mature and emancipated minors the right to make health care decisions without parental consent or notification ${ }^{9,10}$ Second, there are state consent laws based on the type of care that is sought, particularly "sensitive services" such as emergency care, family planning, drug/alcohol, and mental health care. ${ }^{11}$

For nonemergency reproductive health care, Title X clinics have robust confidentiality protections, while other types of clinics are widely variable in their protections. ${ }^{12}$ Consent guidelines for substance abuse or mental health services depend on various criteria. For example, in California a minor can consent to outpatient addiction care if he or she is 12 years or older, deemed clinically competent, and would either present a danger of harm without the treatment or is an alleged victim of incest or child abuse. ${ }^{13}$ The Guttmacher Institute's online resource, "An Overview of Minors' Consent Law," provides a compiled list of all 50 states' legal provisions for minor consent regarding various types of health care decisions (https://www. guttmacher.org/state-policy/explore/overview-minorsconsent-law). ${ }^{10}$

There are certain exceptions to confidentiality protected by law. For example, confidentiality must be breached when a clinician determines that a patient poses a serious danger of violence to themselves or a known victim. ${ }^{14,15}$ Every state also requires reporting of known or suspected emotional, sexual, or physical abuse or neglect. For adolescent care, this category of laws is particularly controversial in the context of consensual sexual activity. Every state specifies when sexual activity of an adult with a minor or between minors is illegal (sometimes called "statutory rape"), and statutes often incorporate patient age, difference in age between patient and partner, whether the older person is in a position of authority, and what sexual acts occurred. ${ }^{16}$ Furthermore, individual cases face considerable judicial discretion in terms of prosecuting and sentencing; for example, even if a parent who discovered a sexual relationship wished to press charges, the prosecution would likely consider the above factors before deciding whether to prosecute and the severity of the charge. ${ }^{17}$ Multiple entities, including the American College of Obstetricians and Gynecologists, American Academy of Family Physicians, and American Academy of Pediatrics, have taken a strong stance that such sexual activity should not be automatically construed as sexual abuse. They argue that careful clinical interview can identify the vast majority of reportable cases of sexual coercion or abuse, and that access to confidential health care is essential and should not be compromised on the basis of statutory rape laws. ${ }^{18}$

\section{Challenges for Health Care Providers}

The aforementioned variability in laws and policies can function as a barrier to providers' understanding of confidentiality as it relates to their practice, which may impede how they discuss confidentiality with their patients. Individual health care providers are also subject to their professional and personal ethical codes regarding confidentiality. In a study of confidentiality in the context of "risky behavior," defined as healthcompromising behaviors pertaining to smoking, alcohol use, drug use, sexual behavior, and suicidal behavior, researchers found that providers may feel ethically obligated to break confidentiality and inform parents of these behaviors if they feel it would result in injurious outcomes to either the patient or others. ${ }^{19}$ Since many teens participate in some level of these risky behaviors, professional judgment is critical in determining the point at which the behavior becomes a significant threat. ${ }^{19}$ 
Though health care providers have considerable responsibility in interpreting laws and professional guidelines, many do not receive adequate training on issues in these laws and policies. ${ }^{2,3,20}$ As a result, they may avoid any discussion of confidentiality. One study showed that even within a single state, only $56 \%$ of surveyed physicians brought up confidentiality with any adolescents. When asked about legal guidelines regarding a 15-year-old patient with a sexually transmitted disease, 31\% responded that they were unsure of guidelines for management of this situation. ${ }^{20}$

Beyond legal complexity and inadequate physician training, there are also institutional policy and administrative challenges that can unintentionally threaten confidentiality. There are emerging challenges created by the electronic medical record (EMR) and patient portals. These systems may not comply with or adapt to the requirements of the state or individual medical practice regarding confidentiality. This can lead to unintentional confidentiality breaches when sharing records among clinicians or health care systems. ${ }^{21}$

Payment for medical services also can threaten breaches of confidentiality when practitioners are required to share details of services with thirdparty payers. When forms authorizing the release of confidential information to the insurance company are signed by adult policyholders, dependent minors on the policy are usually bound by the same agreement and may not know this. ${ }^{22}$ Even when confidentially is maintained at the time of service provision, it can be inadvertently breached when parents receive the bill or insurance statement. ${ }^{5}$

\section{Improving Confidential Adolescent Care}

Though it creates many challenges, the complex governance of health care confidentiality also allows for potential solutions to be approached from multiple directions. Expanding the research base on confidential care for adolescents is key to advancing this issue. There have been several studies surveying physicians' knowledge and practice of confidential care for adolescents; ${ }^{20,23,24}$ however, studies exploring the issue from the patient perspective are rare. The available literature does support that adolescents who are assured of confidentiality by a physician report greater willingness to disclose sensitive information like substance use, mental health, and sexual history, nor to seek future health care, as compared to those for whom confidentiality was not mentioned. ${ }^{2,3}$ However, large-sample studies have been mostly limited to surveys of girls who seek reproductive services at family planning clinics. ${ }^{25}$

Another underexplored topic is parent perspectives on confidentiality, and whether interventions focused around educating parents can effectively bring about gains in confidentiality protections. This is critical because when parents agree that minors should be able to provide consent for health care decision-making, it is much easier to protect confidentiality. Also, parents often play a critical role providing support or opposition to legislators on consent and confidentiality laws.

While research may be forthcoming, the most immediate and effective strategy for health care institutions and providers is to implement known best practices for providing confidential care to adolescents. First and foremost, it is critical that employers train staff in state-specific confidentiality and consent laws and their relationship to institutional and professional ethical standards. ${ }^{19,22-24}$ This can be done through offering continuing medical education (CME) credits or by institutional requirements such as annual training modules. It is important to also train nonclinical staff, as violations have been documented in interactions with pharmacists and other personnel. ${ }^{26}$

Prepared with adequate training, providers should counsel all adolescent patients on the protections and limitations of laws. After being counseled on confidentiality limitations, if an adolescent feels strongly that he or she needs services confidentially, clinicians should be prepared to provide or refer the adolescent to free or low-cost health care services that have confidentiality protections. These include Title $\mathrm{X}$-funded clinics, wherein confidentiality is maintained and charges are determined by a sliding-scale model based on patient (not parental) income. ${ }^{7,12}$

Websites like www.findcare.org can be used to maintain an updated list of referral resources. Providers also can standardize time alone for all adolescent patients and implement a workflow that allows for confidential 
completion of risky-behavior screening tools. These tools, as well as services such as sexually transmitted infection screening, can be instated universally. Providers can obtain a cell number for all adolescent patients and standardize systems for calling them with test results and other medical information. ${ }^{23}$

Providers and institutions can focus on the medical record as another strategy to protect confidentiality. For instance, "consent to treat" forms can be modified to include a parental waiver of parts of the record marked as confidential. ${ }^{27}$ Institutions can consult their EMR vendor to be certain patient portals are properly configured to meet state standards regarding confidentiality for adolescents whose parents and guardians have proxy access to their records. ${ }^{28}$ Institutions establishing or updating an EMR system should consider systems with adolescent-specific modules that can be customized to accommodate the confidentiality needs related to minor adolescents. ${ }^{29}$ For example, EMR systems that allow the separation of confidential and nonconfidential information in patient charts can permit the redaction of confidential information before release to parents. Institutions can change their policies and procedures to ensure that delineation and redaction of confidential information is possible. ${ }^{30}$

These practice-level solutions are critical, but health care leaders also should recognize that, ultimately, robust confidentiality protection for adolescents will require broad coordination among multiple stakeholders beyond the level of individual providers or institutions. In every state there are ongoing legislative advocacy efforts on issues involving mandatory reporting of "statutory rape," consent provisions for alcohol/drug abuse, mental health, and reproductive health services, mature minor statutes, and "health care emancipation" laws, to name just a few. A promising long-term strategy for providers and institutional leaders in creating true systematic change is to engage in these advocacy efforts in support of broader confidentiality protections for adolescents.

\section{Summary}

Despite the benefits of providing confidential health care for adolescents, the American legal and health care systems pose many challenges to protection of this right. Though federal standards provide some baseline protection, differences in state laws and professional frameworks create large variability in confidentiality rights across the country. Potential solutions include change within individual practices and medical institutions as well as multidisciplinary policy change at the legislative level.

\section{Patient-Friendly Recap}

- Maintaining confidentiality for teenage minors receiving health services is an important aspect of ethical clinical practice.

- The authors briefly summarize systemic regulatory and administrative complexities involving adolescent confidentiality and the current challenges faced by health providers.

- Health care institutions are in a position to make internal changes - eg, additional physician training, revision of consent forms, inclusion of useful electronic medical record features - that broaden confidentiality protection for minors.

\section{Acknowledgments}

Jacqueline Bhabha, MSc, JD, of Harvard T.H. Chan School of Public Health, for her valuable feedback and support.

\section{Conflicts of Interest}

None.

\section{References}

1. Michaud PA, Blum RW, Benaroyo L, Zermatten J, Baltag V. Assessing an adolescent's capacity for autonomous decisionmaking in clinical care. J Adolesc Health. 2015;57:361-6. $\underline{\text { CrossRef }}$

2. Ford CA, Thomsen SL, Compton B. Adolescents' interpretations of conditional confidentiality assurances. J Adolesc Health. 2001;29:156-9. CrossRef

3. Ford CA, Millstein SG, Halpern-Felsher BL, Irwin CE Jr. Influence of physician confidentiality assurances on adolescents' willingness to disclose information and seek future health care. A randomized controlled trial. JAMA. 1997;278:1029-34. CrossRef

4. English A, Morreale M. A legal and policy framework for adolescent health care: past, present, and future. Houst $J$ Health Law Policy. 2001;1:63-108.

5. Council on Scientific Affairs, American Medical Association. Confidential health services for adolescents. JAMA. 1993;269:1420-4. CrossRef

6. Hodgkin R, Newell P. Implementation Handbook for the Convention on the Rights of the Child, Third Edition. New York, NY: UNICEF, 2007, p. 205. 
7. Weithorn LA, Campbell SB. The competency of children and adolescents to make informed treatment decisions. Child Dev. 1982;53:1589-98. CrossRef

8. English A, Ford CA. The HIPAA privacy rule and adolescents: legal questions and clinical challenges. Perspect Sex Reprod Health. 2004;36:80-6.

9. American College of Obstetricians and Gynecologists. ACOG Committee Opinion no. 599: Adolescent confidentiality and electronic health records. Obstet Gynecol. 2014;123:1148-50. CrossRef

10. Guttmacher Institute. An overview of minors' consent law. https://www.guttmacher.org/state-policy/explore/overviewminors-consent-law. Accessed February 20, 2018.

11. Greydanus DE, Patel DR. Consent and confidentiality in adolescent health care. Pediatr Ann. 1991;20:80-4. CrossRef

12. English A, Summers R, Lewis J, Coleman C. Confidentiality, Third-Party Billing, \& the Health Insurance Claims Process: Implications for Title $X$. Washington, DC: National Family Planning \& Reproductive Health Association, 2015.

13. California Family Code $\$ 6924$. Enacted in 1992; amended in 2018 (SB 1491, effective Jan. 1, 2019).

14. Shain BN; American Academy of Pediatrics Committee on Adolescence. Suicide and suicide attempts in adolescents. Pediatrics. 2007;120:669-76. CrossRef

15. Kachigian C, Felthous AR. Court responses to Tarasoff statutes. J Am Acad Psychiatry Law. 2004;32:263-73.

16. Madison AB, Feldman-Winter L, Finkel M, McAbee GN. Commentary: consensual adolescent sexual activity with adult partners - conflict between confidentiality and physician reporting requirements under child abuse laws. Pediatrics. 2001;107(2):E16. CrossRef

17. Smith BL, Kercher GA. Adolescent Sexual Behavior and the Law. Huntsville, TX: Sam Houston State University Crime Victims' Institute; 2011, p. 11.

18. American Academy of Family Physicians, American Academy of Pediatrics, American College of Obstetricians and Gynecologists, Society for Adolescent Medicine. Protecting adolescents: ensuring access to care and reporting sexual activity and abuse. J Adolesc Health. 2004;35:420-3. CrossRef
19. Rae WA, Sullivan JR, Razo NP, George CA, Ramirez E. Adolescent health risk behavior: when do pediatric psychologists break confidentiality? J Pediatr Psychol. 2002;27:541-9. CrossRef

20. Ford CA, Millstein SG. Delivery of confidentiality assurances to adolescents by primary care physicians. Arch Pediatr Adolesc Med. 1997;151:505-9. CrossRef

21. Spooner SA; Council on Clinical Information Technology, American Academy of Pediatrics. Special requirements of electronic health record systems in pediatrics. Pediatrics. 2007;119:631-7. CrossRef

22. Litt IF. Adolescent patient confidentiality: whom are we kidding? J Adolesc Health. 2001;29:79. CrossRef

23. McKee MD, Rubin SE, Campos G, O'Sullivan LF. Challenges of providing confidential care to adolescents in urban primary care: clinician perspectives. Ann Fam Med. 2011;9:37-43. CrossRef

24. Talib HJ, Silver EJ, Alderman EM. Challenges to adolescent confidentiality in a children's hospital. Hosp Pediatr. 2016;6:490-5. CrossRef

25. Jones RK, Purcell A, Singh S, Finer LB. Adolescents' reports of parental knowledge of adolescents' use of sexual health services and their reactions to mandated parental notification for prescription contraception. JAMA. 2005;293:340-8. CrossRef

26. Conard LA, Fortenberry JD, Blythe MJ, Orr DP. Pharmacists' attitudes toward and practices with adolescents. Arch Pediatr Adolesc Med. 2003;157:361-5. CrossRef

27. American College of Obstetricians and Gynecologists (educational bulletin). Confidentiality in adolescent health care. Int J Gynaecol Obstet. 1998;63:295-300. CrossRef

28. American Academy of Family Physicians. Adolescent health care, confidentiality. https://www.aafp.org/about/policies/all/ adolescent-confidentiality.html. Accessed February 25, 2018.

29. Anoshiravani A, Gaskin GL, Groshek MR, Kuelbs C, Longhurst CA. Special requirements for electronic medical records in adolescent medicine. J Adolesc Health. 2012;51:409-14. CrossRef

30. Weddle M, Kokotailo P. Adolescent substance abuse. Confidentiality and consent. Pediatr Clin North Am. 2002;49:301-15. CrossRef

(C) 2019 Aurora Health Care, Inc. 